\title{
Refining the Reference Values of Diers 4D Formetric System and Introducing a Qualitative Spine Profile Based on Percentile Ranking
}

\author{
Luc Peeters1, Grégoire Lason', Geert Byttebier², Frank Comhaire ${ }^{3 *}$ \\ ${ }^{1}$ International Academy of Osteopathy, Gent, Belgium \\ ${ }^{2}$ Bioconstat Ltd., Rietorchisstraat, 8, B 9041, Gent, Belgium \\ ${ }^{3}$ Brakelmeersstraat, 18, B 9830 Sint Martens-Latem, Belgium \\ Email: ${ }^{\text {frank@comhaire.com }}$
}

Received 17 August 2015; accepted 18 September 2015; published 21 September 2015

Copyright (C) 2015 by authors and Scientific Research Publishing Inc.

This work is licensed under the Creative Commons Attribution International License (CC BY). http://creativecommons.org/licenses/by/4.0/

\section{c) (i) Open Access}

\begin{abstract}
Background: In order to detect possible abnormalities of the spine posture of an individual patient, it is mandatory to dispose of adequate reference values based on measurements in a normal, symptom-free population. The Diers formetric ${ }^{\circledR}$ system allows for non-invasive and accurate assessment of the vertebral column based on the registration of external aspect of the back surface using the Moiré principle. Objective: To create a qualitative spine profile based on the percentile ranking of measurements obtained by the Diers formetric system taking into account possible confounding factors. Materials and Methods: Statistical analysis of formetric recordings in 216 symptom-free volunteers. Results: Maximal kyphotic angle, maximal scoliotic angle, sagittal imbalance, flèche cervicale, and pelvic inclination are significantly influenced by gender and by body mass index (BMI). A synoptic chart was created presenting the percentile ranking taking into account gender and BMI. The percentile ranking was summarized in both a table with colour code and depicted in a histogram of the individual's Qualitative Spine Profile (QSP). Clinical Significance: Percentile ranking and the Quantitative Spine Profile taking into account gender and BMI should permit a more precise and reliable assessment of possible posture deviations related to the patient's complaints, and may assist the therapist in selecting the best mode of treatment.
\end{abstract}

\section{Keywords}

Diers Formetric System, Spine, Reference Values, Kyphosis, Lordosis, Sagittal Imbalance, Body

\footnotetext{
"Corresponding author.
}

How to cite this paper: Peeters, L., Lason, G., Byttebier, G. and Comhaire, F. (2015) Refining the Reference Values of Diers 4D Formetric System and Introducing a Qualitative Spine Profile Based on Percentile Ranking. Open Journal of Medical Imaging, 5, 150-158. http://dx.doi.org/10.4236/ojmi.2015.53019 


\section{Introduction}

Low back pain is a common health problem in western society [1] and may affect as many as $70 \%$ of the population in the course of life [2]. There is no consensus about the proportion of patients in whom a specific causal factor is detected, such as osteoporosis, infection, fracture or metastasis of the vertebra, herniation of the intervertebral disk, Bechterew's disease, etc. [3]. In approximately 15\% of cases the pain becomes chronic [4].

Several options are available for treating patients suffering from low back pain including physiotherapy, acupuncture, local and epidural infiltrations, analgesics or anti-inflammatory medication, chiropractic and manual therapy, and osteopathy [5]. Before any treatment is initiated the anatomical situation of the spine must be assessed [6], which can reliably be done by means of the non-invasive Diers formetric equipment, which does not imply ionising radiation (Diers international Gmbh, Schlangenbad, Germany,

http://www.diersmedical.com/ProductPage.aspx?p=2). The Diers system deduces the anatomy of the thoracolumbar spine based on the external aspect of the back surface using the Moiré principle, and it can repeatedly be applied without any damage or side effects. The system generates a large number of quantitative variables of angulation, torsion, asymmetry, etc.

In order to detect positional abnormalities of the spine, it is of pivotal importance to compare the specific findings of an individual person with adequate reference values. These reference values should take into account several confounding factors that may influence the "normal" configuration of the spine. Once the distribution of the reference values has been defined, the results of an individual person should be situated in a percentile ranking order for each one of the quantitative variables measured, in comparison with the reference data of the "normal” population. This allows for creating a "qualitative spine profile" (QSP) of the configuration of the vertebral column, revealing possible static abnormalities or weaknesses, which may assist the therapist in adapting and optimising his treatment [7] [8].

The present paper aims at quantifying the influence of gender, BMI and age on the distribution of variables measured by the Diers system, at calculating reference values of a symptom-free population, and at presenting a synoptic qualitative spine profile chart (QSP) that visualises the percentile rank order of particular spine characteristics of an individual person.

\section{Materials and Methods}

A total of 226 symptom-free, healthy volunteers have been investigated using the Diers D-4 equipment. Of these one third were male (mean age: 23.7 years, SD: 3.3 yrs.) and two thirds female (mean age: 23.4 years, SD: 2.9 yrs.). All volunteers gave written informed consent.

The data were made anonymous, recorded into an Excel spreadsheet, and analysed by the MedCalc statistical programme (MedCalc Ltd., Ostend, Belgium) [9]. Measurements, such as trunk torsion, with positive and negative results corresponding to deviation to either the left or the right side, were squared for the calculation of the percentile ranking.

The following statistics were used: calculation of mean and standard deviation, cumulative frequency distribution, students t-test for independent variables, correlation coefficients for parametrical data, and calculation of percentile ranking [10]. Body mass index (BMI) was calculated by dividing body weight (in kilogram) by the square of length (in meter) and expressed as $\mathrm{kg} / \mathrm{m}^{2}$ [11].

\section{Results}

\subsection{Gender}

There is a significant difference between women and men regarding the maximal kyphotic $(\mathrm{P}=0.034)$ and lordotic angulations $(\mathrm{P}<0.0001)$, as is evidenced by the position of the curves of cumulative frequency distribution (Figure 1, Figure 2), but this is not the case for trunk torsion, nor for sagittal imbalance. 


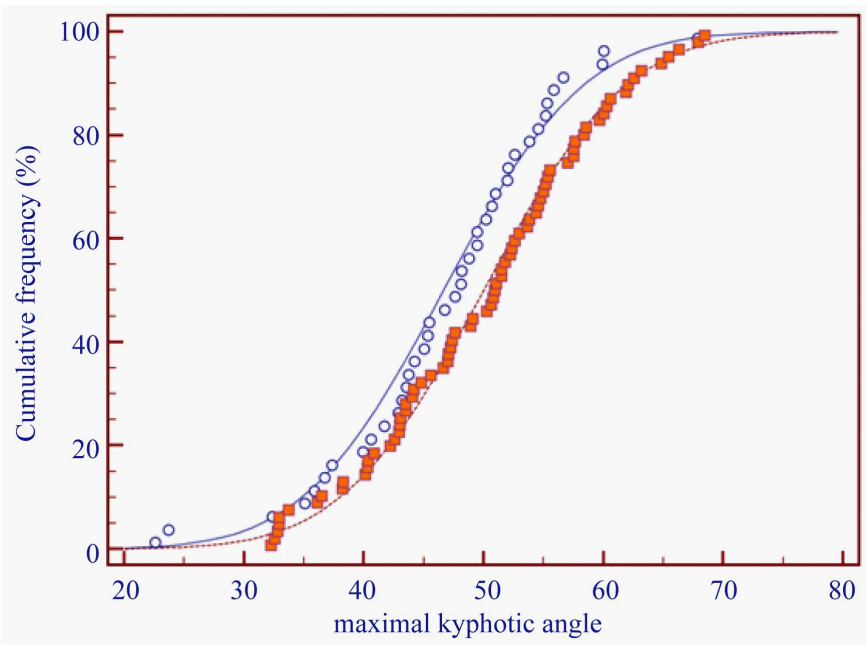

Figure 1. Curves of cumulative frequency distribution of maximal kyphotic angle (on the horizontal axis, in degrees) in men (blue open circles) and women (red filled squares). The figure represents the actual data and the respective curves of normal distribution. The cumulative frequency distribution curve of women is situated more to the right indicating higher angles.

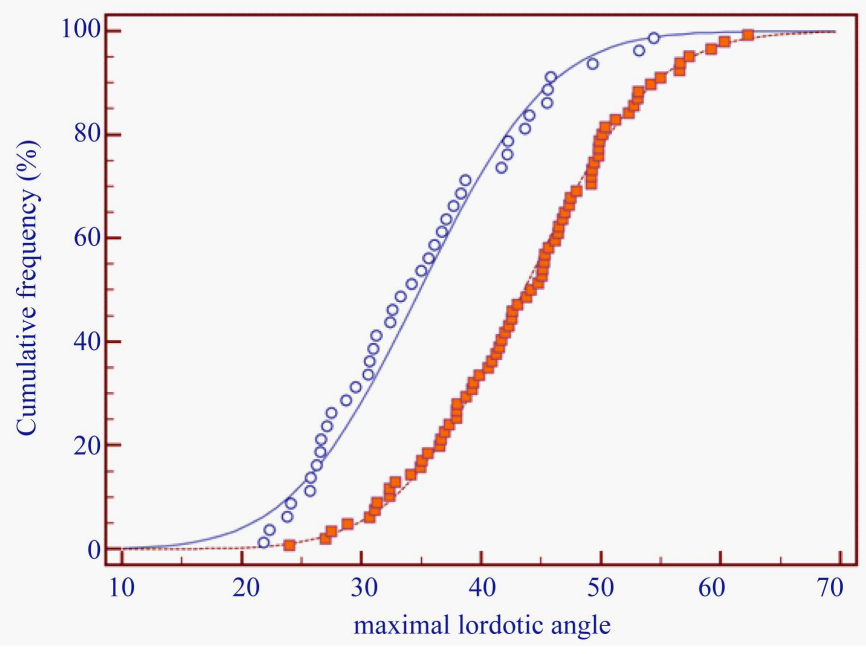

Figure 2. Curves of cumulative frequency distribution of the maximal lordotic angle (on the horizontal axis, in degrees). The curve of women is situated far more to the right indicating importantly higher values in women than in men.

\subsection{Body Mass Index (BMI)}

BMI was significantly correlated with the maximal lordotic angle $(r=0.19, \mathrm{P}=0.041)$, with the maximal kyphotic angle $(r=0.22, P=0.016)$, and with sagittal imbalance $(r=0.50, P<0.0001)$, whereby lordotic and kyphotic angle were mutually correlated $(\mathrm{r}=0.37, \mathrm{P}=0.0001)$.

The population was divided into 3 conventional groups: group 0 with normal BMI between 19 and $25 \mathrm{~kg} / \mathrm{m}^{2}$ (n = 27), group 1 with overweight and BMI between $25 \mathrm{~kg} / \mathrm{m}^{2}$ and $30 \mathrm{~kg} / \mathrm{m}^{2}(\mathrm{n}=27)$, and group 2 with obesity and BMI of $30 \mathrm{~kg} / \mathrm{m}^{2}$ or higher $(\mathrm{n}=21)$.

The cumulative frequency distribution curves were significantly different in respect to the following variables:

The sagittal imbalance (Figure 3) was higher in BMI group 2 than in group 1, and in group 1 than in group 0, 


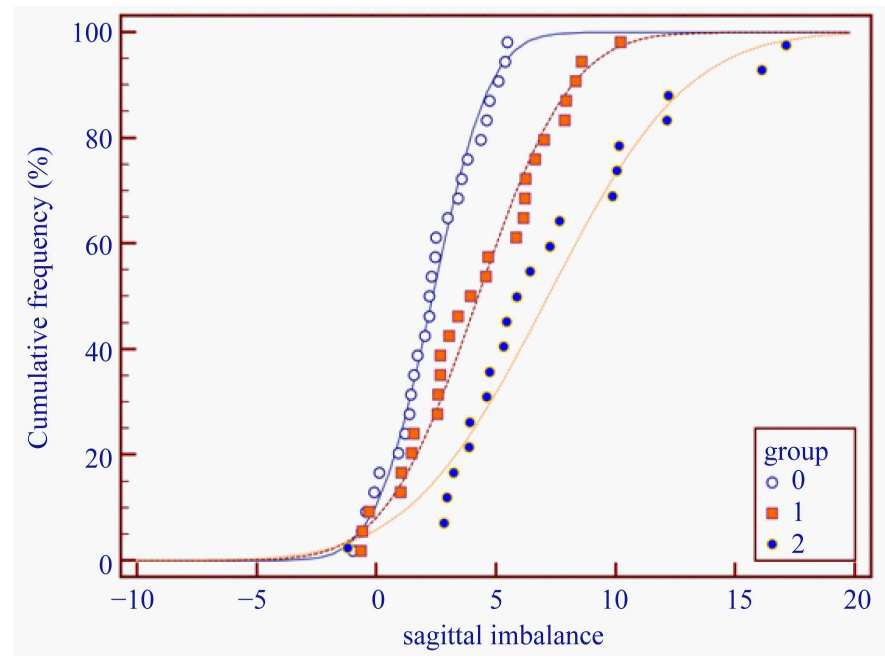

Figure 3. Curves of cumulative frequency distribution of the sagittal imbalance (on the horizontal axis, in degrees) in the 3 groups of body mass index (BMI). The curve of persons with normal BMI (group $=0$, BMI $<25 \mathrm{~kg} / \mathrm{m}^{2}$ ) is situated most to the left indicating lower values. The curve of persons with overweight (group $=1$, BMI between 25 and $30 \mathrm{~kg} / \mathrm{m}^{2}$ ) is in the middle, with values higher than persons of group $=0$, but lower than persons of group $=2$. The curve most to the right corresponds to persons of group $=2$, with obesity and BMI $>30$ $\mathrm{kg} / \mathrm{m}^{2}$ who present the highest sagittal imbalance.

confirming the positive correlation between BMI and sagittal imbalance, and suggesting higher forward inclination of the trunk as BMI increases.

The "flèche cervicale" was higher as BMI increased (Figure 4), confirming forward inclination, and the flèche cervicale was significantly correlated with the sagittal imbalance $(\mathrm{r}=0.65, \mathrm{P}<0.0001)$ (Figure 5).

The maximal kyphotic angle was higher among persons with BMI of $25 \mathrm{~kg} / \mathrm{m}^{2}$ or more (groups 1 and 2) as compared to group 0 with BMI $<25 \mathrm{~kg} / \mathrm{m}^{2}$, but there was no difference between the groups 1 and 2 (Figure 6). The kyphotic angle was significantly correlated with the flèche cervicale $(r=0.49, \mathrm{P}<0.001)$ and with the sagittal imbalance $(\mathrm{P}<0.0001)$.

The pelvic inclination was lower in the persons with BMI $>30 \mathrm{~kg} / \mathrm{m}^{2}$, than in the two other groups, which are not different mutually (Figure 7). It was negatively correlated with flèche cervicale $(r=-0.34, P=0.003)$, but not with sagittal imbalance, nor with the kyphotic angle.

Although the maximum lordotic angle was significantly correlated with the kyphotic angle $(\mathrm{r}=0.39, \mathrm{P}<$ $0.0001)$ there was no significant difference of the former between BMI-groups $(\mathrm{P}=0.29)$.

\subsection{Age}

There was no influence of age, since the mean and median values of variables did not indicate differences between younger and older persons regarding lordosis, kyphosis and sagittal imbalance. Also age was not correlated with BMI.

\section{Percentile Ranking}

Two determinants need to be included in order to create specific reference values, namely gender (2 classes) and BMI (3 classes). Gender, height and weight should be registered for every new case and BMI is calculated automatically by the computer programme. These data are connected with the relevant variables generated by the Diers system.

The percentile rank of a measured value is the percentage of values in its frequency distribution that are the same or lower than it. For example, a result that is greater than or equal to $75 \%$ of the scores of people taking the test is said to be at the 75th percentile rank. Thus, the measured variables are compared with the reference values 


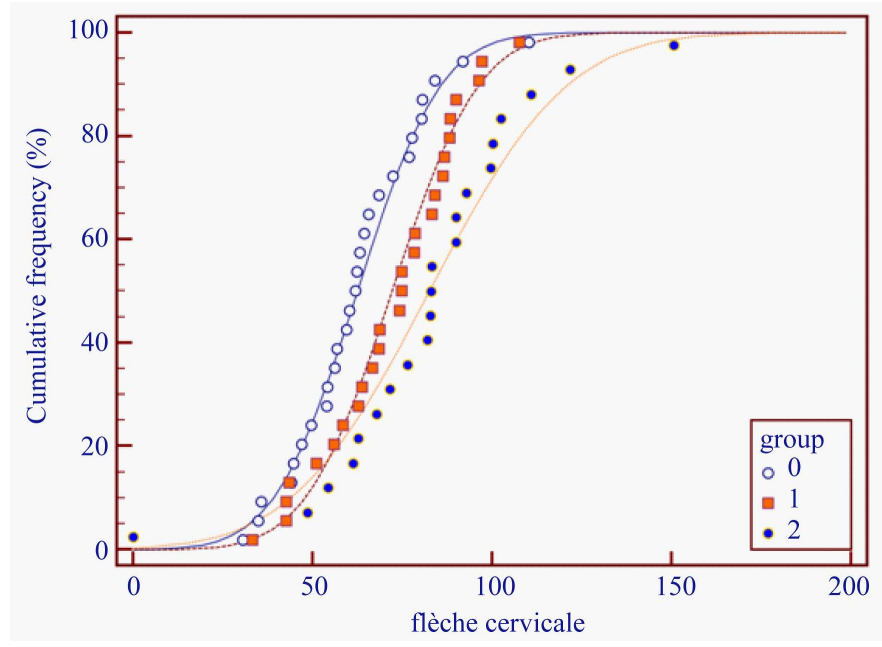

Figure 4. Depicts the cumulative frequency distribution curves of flèche cervicale (on the horizontal axis, in $\mathrm{mm}$ ) of the 3 BMI-groups. Legends as in Figure 3.

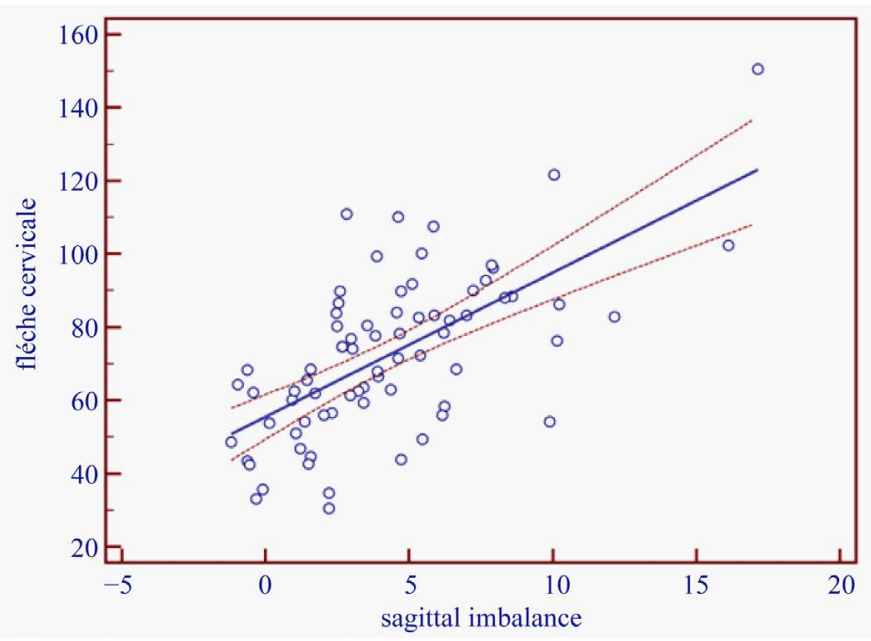

Figure 5. Distribution plot of the correlation between sagittal imbalance (on the horizontal axis, in degrees) and the flèche cervicale (on the vertical axis, in $\mathrm{mm}$ ) in all cases. The regression in and its $95 \%$ confidence intervals are shown $(r=0.65, \mathrm{P}<0.0001)$.

of the subgroup to which the person belongs, and the percentile rank is generated. The percentile rankings are presented in an overview synoptic histogram (Figure 8).

\section{Discussion}

The correlation between kyphotic angle and lordotic angle confirms the concept described as reciprocal angulation of vertebral bodies in the sagittal plane [12].

The present data confirm our previous results regarding the effect of gender on spine configuration (Lason et al., in press, International Journal of Osteopathy 2015) and underscore the need to include gender information into the evaluation of reference values.

The absence of influence of age on spine curvatures is in agreement with results published by others [13] [14] in adults, and in children [15]. In contrast, Youdas et al. [16] reported an effect of age on standing lumbar curvatures in persons between 20 and 79 years of age, but this effect was only significant when comparing the age group of 20 to 29 years with the age group of 50 to 59 years. 


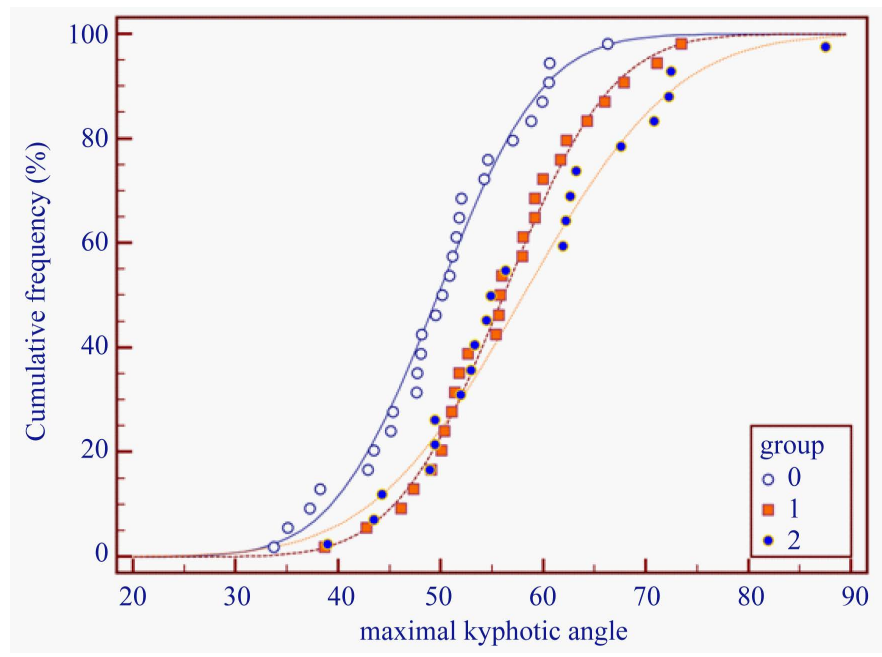

Figure 6. Cumulative frequency distribution curves of the maximal kyphotic angle (on the horizontal axis, in degrees) in the 3 groups of BMI. The curve of group $=0$, with BMI $<25 \mathrm{~kg} / \mathrm{m}^{2}$ is situated more to the left of the curves of groups 1 and 2 . The latter are not significantly different mutually.

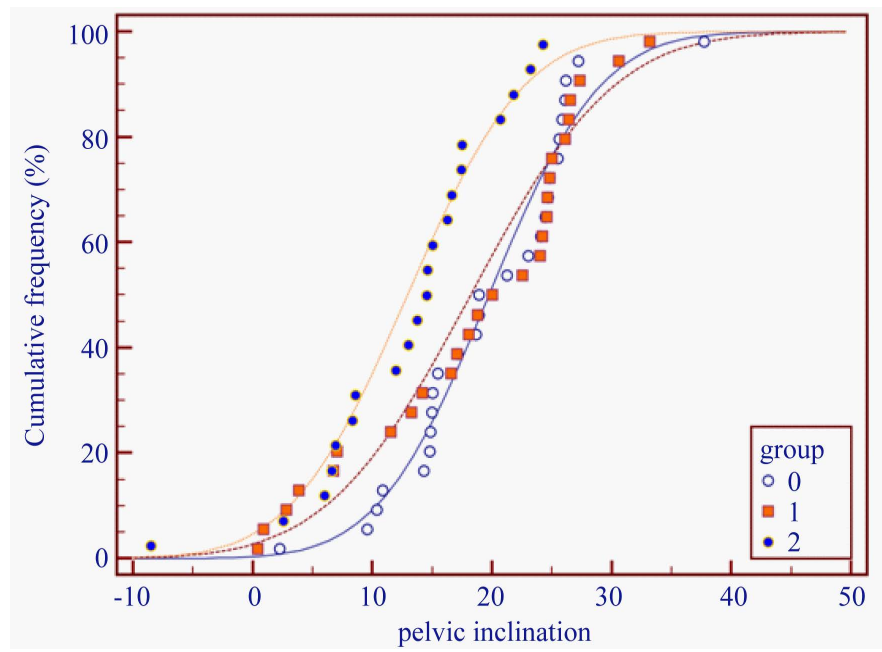

Figure 7. Cumulative frequency distribution curves of pelvic inclination (on the horizontal axis, in degrees) according to the BMI. The curve of group $=2$, with obesity and BMI $>30 \mathrm{~kg} / \mathrm{m}^{2}$ is situated to the left of the curves of groups 0 and 1 , which are not significant mutually. This indicates that the pelvic inclination is lower in persons with obesity than in persons with overweight (group $=1$ ) or with normal body mass index (group 0, BMI < 25).

The ratio of body weight with height is expressed in the Quetelet index or body mass index (BMI), though this may not be an optimal marker for body fat percentage and to identify obesity [17]. Increasing BMI has an important influence and is associated with forward inclination of the trunk as evidenced by increased flèche cervicale and sagittal imbalance, as well as increased thoracic kyphosis. The latter occurs already when the BMI exceeds $25 \mathrm{~kg} / \mathrm{m}^{2}$. On the other hand, pelvic inclination is lower in persons with BMI exceeding $30 \mathrm{~kg} / \mathrm{m}^{2}$. Whereas forward inclination of the trunk can logically be expected due to imbalance from overweight and obesity, the decreased pelvic inclination with inverse relation to the fleche cervical is more difficult to explain, though it may result from stronger compensatory fixation of the lumbo-sacral segment. Whereas Youdas et al. [16] found no significant effect of BMI, Romero-Vargas et al. [18] detected a non-significant effect of obesity 


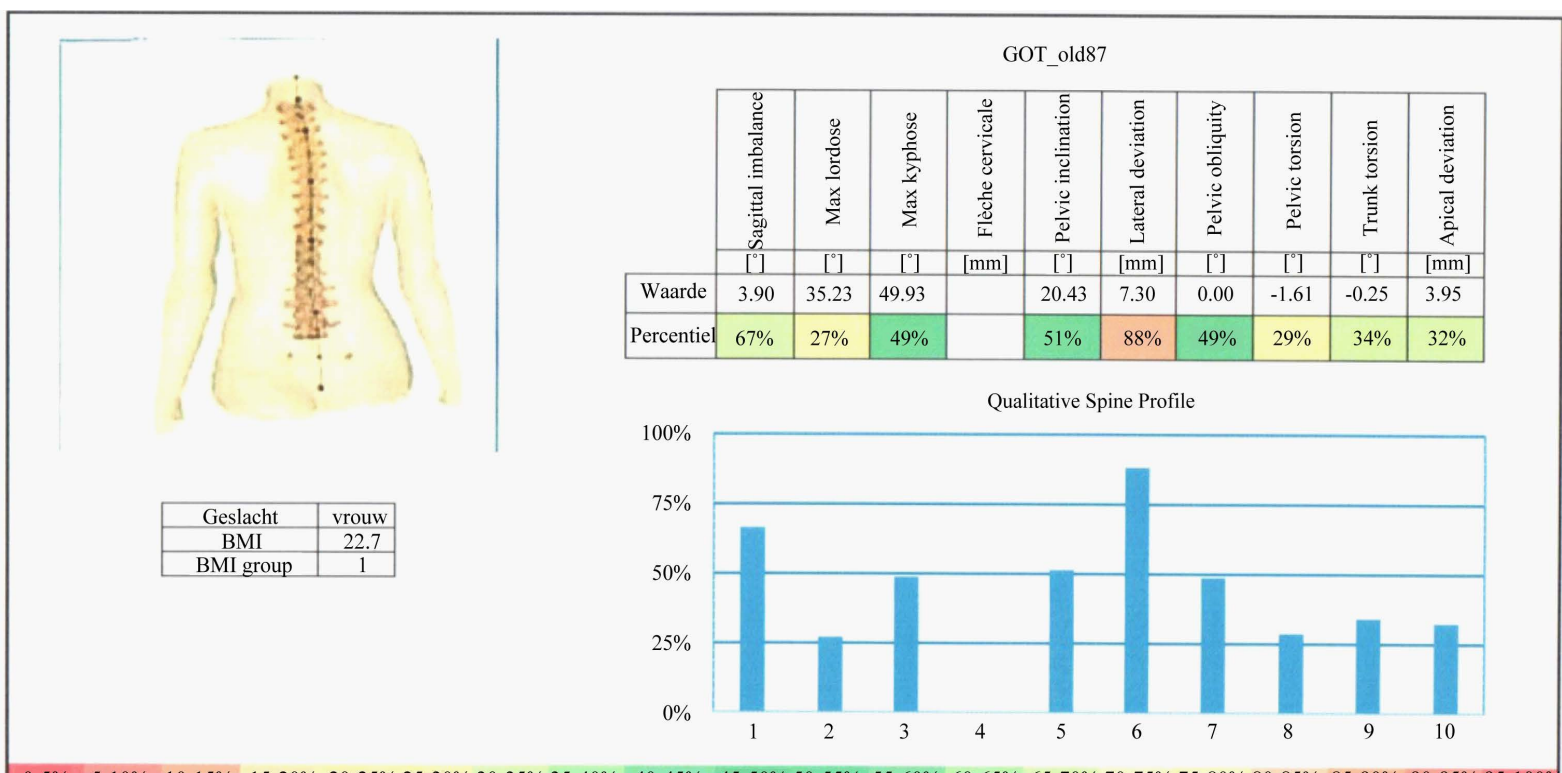

Figure 8. Qualitative Spine Profile (QSP) chart of a symptom-free volunteer identified as GOT-old87, being female (vrouw) with BMI (calculated by the software) of $22.7 \mathrm{~kg} / \mathrm{m}^{2}$ and, therefore, belonging to group 0 . In the upper left corner the image of the vertebral column generated by the Diers system is represented. The table lists the measured values of the five fixed variables, namely: sagittal imbalance, maximal lordotic angle, maximal kyphotic angle, flèche cervicale, pelvic inclination, as well as of the 5 variables selected by the investigator namely: lateral inclination, pelvic obliquity, pelvic torsion, trunk torsion and apical deviation. For each one of the variable the corresponding percentile rank is plotted below the measured value, whereby percentile ranking of torsion measurements is based on the squared value. The histogram depicts the percentile rankings of each variable. It can be seen that in this person the sagittal inclination, maximum kyphotic angle, pelvic inclination and pelvic obliquity are close to the median values of the reference population of women with BMI between 19 and 25 . Maximal lordotic angle, pelvic torsion, trunk torsion and apical deviation are situated at or near the $25^{\text {th }}$ percentile. Lateral deviation is high, and flèche cervicale has not been measured. The percentile values are also marked with colours in accordance with the colour scale indicated at the bottom of the chart.

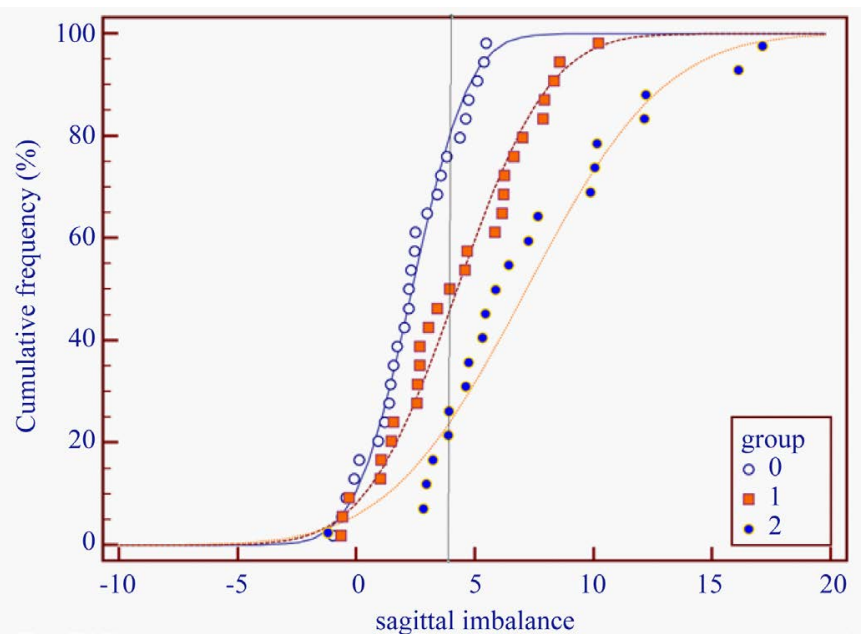

Figure 9. This figure illustrates the importance of considering BMI when interpreting the sagittal imbalance in an individual person. The curves of cumulative frequency distribution represent the sagittal inclination (on the horizontal axis, in degrees) in the 3 BMI groups (see also Figure 3). A person with sagittal inclination of e.g. $4^{\circ}$ and BMI $<25$ (group $=0$ ) will be ranked on approximately the 80st percentile, indicating a relative high degree of imbalance as compared to his peers with the same BMI. If a person with the same sagittal inclination of $4^{\circ}$ belongs to BMI group 1 (overweight) the sagittal imbalance will be situated at approximately the 50st percentile, corresponding to the median of his BMI-group. A person with the same sagittal imbalance and belonging to the obesity-group $=2$ will rank at approximately the 20st percentile of his group, and therefore his sagittal imbalance will be considered relatively low. 
on lumbar lordosis using a radiographic method. Others reported a significant effect of BMI on lordosis and kyphosis [19] [20]. In addition, obesity and overweight have commonly been reported in association with low back pain [21]-[24], possibly related to hyperlordotic posture [25].

It could be argued that the higher kyphotic angle in persons with overweight or obesity may be due to the fact that women have, on an average, a lower BMI [26] [27]. However, women having a higher kyphotic angle than men, this would be associated with the opposite effect, namely a higher kyphotic angle in the normal BMI-group. Hence, gender and BMI seem to independently influence the sagittal spine angulations.

In relation to the goal of the present study, the difference in posture related with BMI should be considered when evaluating the results of any individual person and be taken into account when ranking the individual measurements in a percentile order.

Indeed, there is a major difference in percentile ranking between a person with sagittal imbalance of e.g. $4^{\circ}$ and BMI $<25 \mathrm{~kg} / \mathrm{m}^{2}$ compared to the same degree of imbalance in a person with BMI $>30 \mathrm{~kg} / \mathrm{m}^{2}$ (Figure 9). Whereas the sagittal imbalance of first person ranks at the 80st percentile, and is relatively high in comparison with his peers, that of the second person ranks at approximately the 25st percentile, which is relatively low. A person with sagittal imbalance of $4^{\circ}$ and BMI between 25 and 30 will rank at the 50st percentile, corresponding to the median value for his BMI-group.

Finally, an example is shown of the image obtained by the Diers system and the corresponding QSP, taking into account the gender and the BMI of that particular person (Figure 8). The QSP always contains the 5 measured variables, the percentile ranking of which is influenced by gender and BMI, and is completed with 5 additional variables which can be freely selected by the investigator.

\section{References}

[1] Andersson, G.B. (1999) Epidemiological Features of Chronic Low-Back Pain. Lancet, 354, 581-585. http://dx.doi.org/10.1016/S0140-6736(99)01312-4

[2] Hoy, D., Brooks, P., Blyth, F., et al. (2010) The Epidemiology of Low Back Pain. Best Practice \& Research Clinical Rheumatology, 24, 769-781. http://dx.doi.org/10.1016/j.berh.2010.10.002

[3] DePalma, M.J., Ketchum, J.M. and Saullo, T. (2011) What Is the Source of Chronic Low Back Pain and Does Age Play a Role? Pain Medicine, 12, 224-233. http://dx.doi.org/10.1111/j.1526-4637.2010.01045.x

[4] Parleviet, T. (2014) Oefentherapie Voor Chronische Aspecifieke Rugklachten (Exercisetherapyforchronic Non- Specific Low Back Pain). Tijdschrift voor Geneeskunde, 70, 685-690.

[5] Andersson, G.B., Lucente, T., Davis, A.M., et al. (1999) A Comparison of Osteopathic Spinal Manipulation with Standard Care for Patients with Low Back Pain. New England Journal of Medicine, 341, 1426-1431. http://dx.doi.org/10.1056/NEJM199911043411903

[6] Tsuji, T., Matsuyama, Y., Sato, K., et al. (2001) Epidemiology of Low Back Pain in the Elderly: A Correlation with Lumbar Lordosis. Journal of Orthopaedic Science, 6, 307-311. http://dx.doi.org/10.1007/s007760100023

[7] Mitchell, T., O’Sullivan, P.B., Burnet, A.F., et al. (2008) Regional Differences in Lumbar Spinal Posture and the Influence of Low Back Pain. BMC Musculoskeletal Disorders, 9, 152. http://dx.doi.org/10.1186/1471-2474-9-152

[8] Licciardone, J.K., Kearns, C.M. and Crow, W.T. (2014) Changes in Biomechanical Dysfunction and Low Back Pain Reduction with Osteopathic Manual Treatment: Results from the OSTEOPATHIC Trial. Manual Therapy, 19, 324330. http://dx.doi.org/10.1016/j.math.2014.03.004

[9] Schoonjans, F., Zalata, A., Depuydt, C.E., et al. (1995) MedCalc: A New Computer Program for Medical Statistics. Computer Methods and Programs in Biomedicine, 48, 357-362. http://dx.doi.org/10.1016/0169-2607(95)01703-8

[10] Schoonjans, F., De Bacquer, D. and Schmid, P. (2011) Estimation of Population Percentiles. Epidemiology, 22, 750751. http://dx.doi.org/10.1097/EDE.0b013e318225c1de

[11] Quetelet, A. (1835) Essai de physique sociale. Sur l’homme et le développement de ses facultés. Bachelier, imprimeurlibraire, Paris.

[12] Lundberg, G. and Gerdle, B. (1999) The Relation between Spinal Sagittal Configuration, Joint Mobility, General Low Back Mobility and Segmental Mobility in Female Homecare Personnel. Scandinavian Journal of Rehabilitation Medicine, 31, 197-206. http://dx.doi.org/10.1080/003655099444362

[13] Schroeder, J., Schaar, H. and Mattes, K. (2013) Spinal Alignment in Low Back Pain Patients and Age-Related Side Effects: A Multivariate Cross-Sectional Analysis of Video Rasterstereography Back Shape Reconstruction Data. European Spine Journal, 22, 1979-1985. http://dx.doi.org/10.1007/s00586-013-2787-4

[14] Murrie, V.L., Dixon, A.K., Hollingworth, W., Wilson, H. and Doyle, T.A.C. (2003) Lumbar Lordosis: Study of Pa- 
tients with and without Low Back Pain. Clinical Anatomy, 16, 144-147. http://dx.doi.org/10.1002/ca.10114

[15] Furian, T.C., Rapp, W., Eckert, S., Wild, M. and Betsch, M. (2013) Spinal Posture and Pelvic Position in Three Hundred Forty-Five Elementary School Children: A Rasterstereographic Pilot Study. Orthopedic Reviews, 5, e7. http://dx.doi.org/10.4081/or.2013.e7

[16] Youdas, J.W., Hollman, J.H. and Krause, D.A. (2006) The Effects of Gender, Age, and Body Mass Index on Standing Lumbar Curvature in Persons without Current Low Back Pain. Physiotherapy Theory and Practice, 22, 229-237. http://dx.doi.org/10.1080/09593980600927864

[17] Akpinar, E., Bashan, I., Bozdemir, N. and Saatci, E. (2007) Which Is the Best Anthropometric Technique to Identify Obesity: Body Mass Index, Waist Circumference or Waist-Hip Ratio? Collegium Antropologicum, 31, 387-393.

[18] Romero-Vargas, S., Zarate-Kalfopulos, B., Otero-Camara, E., Rosales-Olivarez, L., Alpízar-Aguirre, A., MoralesHernández, E. and Reyes-Sánchez, A. (2013) The Impact of Body Mass Index and Central Obesity on the Spino-Pelvic Parameters: A Correlation Study. European Spine Journal, 22, 878-882. http://dx.doi.org/10.1007/s00586-012-2560-0

[19] Guo, J.M., Zhang, G.Q. and Alimuljang (2008) Effect of BMI and WHR on Lumbar Lordosis and Sacrum Slant Angle in Middle and Elderly Women. Zhongguo Gu Shang, 21, 30-31.

[20] Lang-Tapia, M., Espana-Romero, V., Anelo, J. and Castillo, M.J. (2011) Difference on Spinal Curvature in Standing Position by Gender, Age and Weight Status Using a Noninvasive Method. The Journal of Applied Biochemistry, 27, 143-150.

[21] Deyo, R.A. and Bass, J.E. (1989) Lifestyle and Low-Back Pain. The Influence of Smoking and Obesity. Spine, 14, 501-506. http://dx.doi.org/10.1097/00007632-198905000-00005

[22] Shiri, R., Karppinen, J., Leino-Arjas, P., Solovieva, S. and Viikari-Juntura, E. (2010) The Association between Obesity and Low-Back Pain: A Meta-Analysis. American Journal of Epidemiology, 171, 134-154. http://dx.doi.org/10.1093/aje/kwp356

[23] Duruöz, M.T., Turan, Y., Gürgan, A. and Deveci, H. (2012) Evaluation of Metabolic Syndrome in Patients with Chronic Low Back Pain. Rheumatology International, 32, 663-667. http://dx.doi.org/10.1007/s00296-010-1693-X

[24] Heuch, I., Heuch, I., Hagen, K. and Zwart, J.-A. (2013) Body Mass Index as a Risk Factor for Developing Chronic Low Back Pain: A Follow-Up in the North-Trodelag Health Study. Spine, 38, 133-139. http://dx.doi.org/10.1097/BRS.0b013e3182647af2

[25] Smith, A.J., O’Sullivan, P.B., Beales, D.J., de Klerk, N. and Straker, L.M. (2011) Trajectories of Childhood Body Mass Index Are Associated with Adolescent Sagittal Standing Posture. International Journal of Pediatric Obesity, 6, e97-e106. http://dx.doi.org/10.3109/17477166.2010.530664

[26] Kuczmarski, R.J., Carroll, M.D., Flegal, K.M., and Troiano, R.P. (1997) Varying Body Mass Index Cutoff Points to Describe Overweight Prevalence among U.S. Adults: NHANES III (1988 to 1994). Obesity Research, 5, 542-548. http://dx.doi.org/10.1002/j.1550-8528.1997.tb00575.x

[27] Flegal, K.M. (2006) Body Mass Index of Healthy Men Compared with Healthy Women in the United States. International Journal of Obesity, 30, 374-379. http://dx.doi.org/10.1038/sj.ijo.0803117 